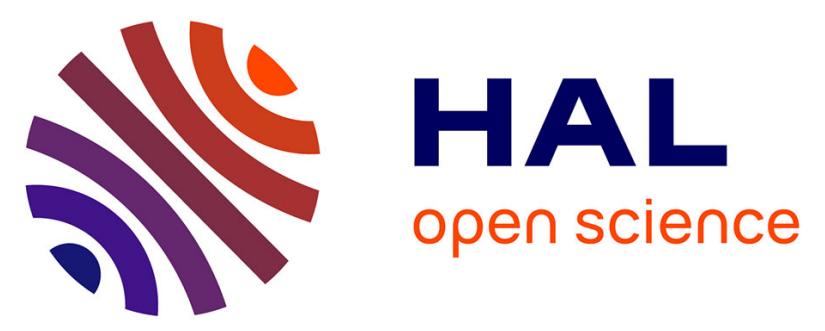

\title{
Constructing 3D CNTs-SiO2@RGO structures by using GO sheets as template
}

\author{
Yu Liu, Yiguo Xu, Benhui Fan, Minhao Yang, Ann-Lenaig Hamon, Paul \\ Haghi-Ashtiani, Delong He, Jinbo Bai
}

\section{- To cite this version:}

Yu Liu, Yiguo Xu, Benhui Fan, Minhao Yang, Ann-Lenaig Hamon, et al.. Constructing 3D CNTsSiO2@RGO structures by using GO sheets as template. Chemical Physics Letters, 2018, 713, pp.189193. 10.1016/j.cplett.2018.10.047 . hal-01960225

\section{HAL Id: hal-01960225 \\ https://hal-centralesupelec.archives-ouvertes.fr/hal-01960225}

Submitted on 20 Apr 2020

HAL is a multi-disciplinary open access archive for the deposit and dissemination of scientific research documents, whether they are published or not. The documents may come from teaching and research institutions in France or abroad, or from public or private research centers.
L'archive ouverte pluridisciplinaire HAL, est destinée au dépôt et à la diffusion de documents scientifiques de niveau recherche, publiés ou non, émanant des établissements d'enseignement et de recherche français ou étrangers, des laboratoires publics ou privés. 


\section{Constructing 3D CNTs-SiO ${ }_{2} @$ GNP structures by using GO sheets as}

\section{template}

Yu LIU, Yiguo XU, Benhui FAN, Ann-Lenaig HAMON, Paul HAGHI-ASHTIANI, Delong HE* and Jinbo BAI*

Laboratoire Mécanique des Sols, Structures et Matériaux (MSSMat), CNRS UMR 8579, CentraleSupélec, Université ParisSaclay, 3 rue Joliot-Curie, 91190 Gif-sur-Yvette Cedex, France

Corresponding email: jinbo.bai@centralesupelec.fr, delong.he@centralesupelec.fr

\section{Abstract}

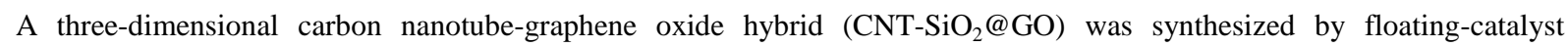
chemical vapor deposition (CVD), in which ferrocene was used as catalyst precursor, acetylene as carbon source, respectively. graphene oxide (GO) was pre-treated by tetraethyl orthosilicate (TEOS) to deposit a $\mathrm{SiO}_{2}$ layer on both side of the platelet surface. The morphology, structure and component were investigated by scanning electron microscope, transmission electron microscope and thermogravimetric analysis. The obtained hybrid has a uniform structure with a platelet sandwiched by aligned CNTs vertical to its surface. The length of CNT can be well controlled by the variation of growth time. The growth mechanism was also elaborated by comparing the GO substrates before and after TEOS treatment.

Keywords: CVD, $\mathrm{SiO}_{2} @ \mathrm{GO}, \mathrm{CNT}-\mathrm{GO} @ \mathrm{SiO}_{2}$ hybrid

\section{Introduction}

Graphene has received tremendous attention from both the experimental and the theoretical scientific communities due to its unique electrical, thermal and mechanical properties. It provides an ideal fillers to prepare functional materials for a wide range of applications [1]. However, their applications have been limited by its industrial production, both in quality and quantity. Due to the ultra-high specific surface, graphene tends to form aggregation and reduce its pristine performance. Many methods have been developed to prepare graphene. Among them, the oxidation and reduction of graphite is one of the most effective methods in mass production of graphene [2]. However, the reduction of GO leads to irreversible agglomeration and precipitation [3]. As a result, the unique 2D feature of graphene would be lost. Besides, due to the thin thickness, graphene tends to aggregate in the matrix when fabricating into composites which reduces its pristine performances. Thus, large amounts of works have been focused on better using excellent properties of graphene by exploiting 3D structures of graphene based hybrids.

Attentions to combining CNTs and graphene have been attracted to prepare graphene-CNT reinforced composites for different applications $[4,5]$. Significant property enhancement has been achieved in these materials with the existence of CNTs which are believed to bridge the defects for electron transfer and, in the meantime, to increase the basal spacing between graphene sheets. In recent years, a 3D carbon material, consisting of parallel graphene layers stabilized by vertically aligned CNTs on the graphene planes (CNT-GNP), has been fabricated by CVD method. The CNT-GNP has been used as reinforced fillers in various kinds of materials $[6,7]$. However, experimental investigation has demonstrated that most cases of growing CNTs on graphite substrates is not uniform due to the poor wettability between graphite surface and catalyst 
particles, which results in aggregation. Meanwhile, coalescence of the catalyst particles always happens on the graphite substrate during sintering which also affects the homogeneous distribution of CNT on graphite substrates.

Therefore, how to improve the wettability between graphite surface and catalyst particles as well as avoiding coalescence as much as possible become a crucial point to prepare CNT-GNP hybrid. In this work, a uniform layer of $\mathrm{SiO}_{2}$ was first covalently bonded to the GO surface by a typical sol-gel method. Then, the CVD process was conducted to grow CNT on the $\mathrm{SiO}_{2} @ \mathrm{GO}$ surface. (In this work, oxide graphene (GO) with a layer of $\mathrm{SiO}_{2}$ prepared by sol-gel method will be uses instead of graphite as a substrate to grow CNT by CVD.) The length and density of CNT array growing on the $\mathrm{SiO}_{2} @ \mathrm{GO}$ will be controlled by the synthesis time and the morphology and component will be investigated by electron microscope and TGA, respectively.

\section{Experiment}

\subsection{Samples preparation}

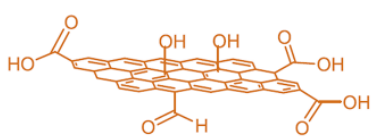

(GO)

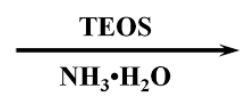

$\mathrm{NH}_{3} \cdot \mathrm{H}_{2} \mathrm{O}$

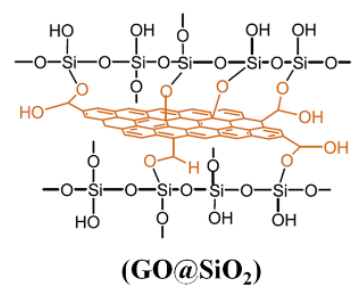

$\left(\mathrm{GO} @ \mathrm{SiO}_{2}\right)$

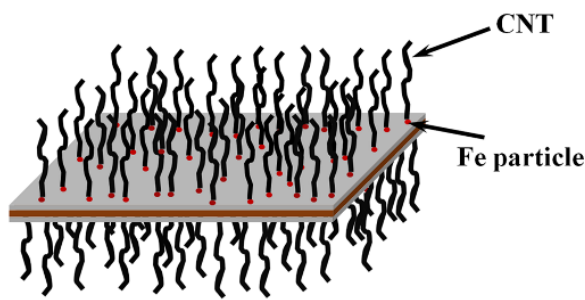

(CNT-GO@SiO

Scheme 1 Illustration of the formation of CNT-SiO ${ }_{2} @$ GO hybrid.

$\mathrm{SiO}_{2} @ \mathrm{GO}$ was prepared by a typical sol-gel method [8], as shown in Scheme 1. $100 \mathrm{mg}$ GO (GO-V50, GRAPHENE STANDRAD) was loaded in a $400 \mathrm{~mL}$ flask, to which ethanol $(210 \mathrm{~mL})$ and distilled water $(30 \mathrm{~mL})$ were added. After ultrasonic agitation for $1 \mathrm{~h}$, several drops of ammonium hydroxide (30\%, Aladdin) were added to the dispersion under stirring to adjust the $\mathrm{pH}$ to 9.0. Then, $1 \mathrm{~mL}$ of tetraethyl orthosilicate (TEOS, Aladdin) was added dropwise and stirred for $16 \mathrm{~h}$ at room temperature. Finally, the product was centrifuged and further washed with $96 \%$ ethanol solution three times, respectively. The resulting precipitates were dried in a vacuum oven at room temperature for $6 \mathrm{~h}$ to obtain $\mathrm{SiO}_{2} @ \mathrm{GO}$ powders. The hybrids were synthesized by the floating-catalyst CVD method. Acetylene was selected as carbon source, and ferrocene was served as catalyst precursor for the growth of CNTs. The synthesis temperature was fixed at $650{ }^{\circ} \mathrm{C}$ and the synthesis time were varied from $5 \mathrm{~min}$ to $10 \mathrm{~min}$.

\subsection{Characterization}


The microstructure of hybrids and GO derivatives was observed by scanning electron microscope (SEM) (ZEISS, LEO 1530 Gemini) at $20 \mathrm{kV}$. Scanning transmission electron microscope (STEM) imaging was performed using a Titan ${ }^{3}$ G2 (FEI) with a bright field emission gun (XFEG) operating at the accelerating voltage of $200 \mathrm{kV}$. Energy-dispersion X-ray microscopy (EDX) was carried out on the same equipment and operated at $200 \mathrm{kV}$ in a STEM mode. The EDX maps were acquired for 10min. Thermogravimetric analysis (TGA, NETZSCH STA 443 F3) was used to evaluate the mass fraction of CNTs grafted on the $\mathrm{SiO}_{2} @ \mathrm{GO}$ surface. Around $4 \mathrm{mg}$ sample was heated from $30{ }^{\circ} \mathrm{C}$ to $800{ }^{\circ} \mathrm{C}$ at a rate $0 f 10{ }^{\circ} \mathrm{C} / \mathrm{min}$. The atmosphere was a mixture of oxygen and nitrogen, with a flow rate of $20 \mathrm{~mL} / \mathrm{min}$. Raman Spectrometer (LabRAM HORIBA Jobin Yvon, Edison, NJ, USA) excited by the $633 \mathrm{~nm}$ coherent line of a He:Ne laser was used to evaluated the carbon structure of the samples at room temperature.

\section{Results and discussion}
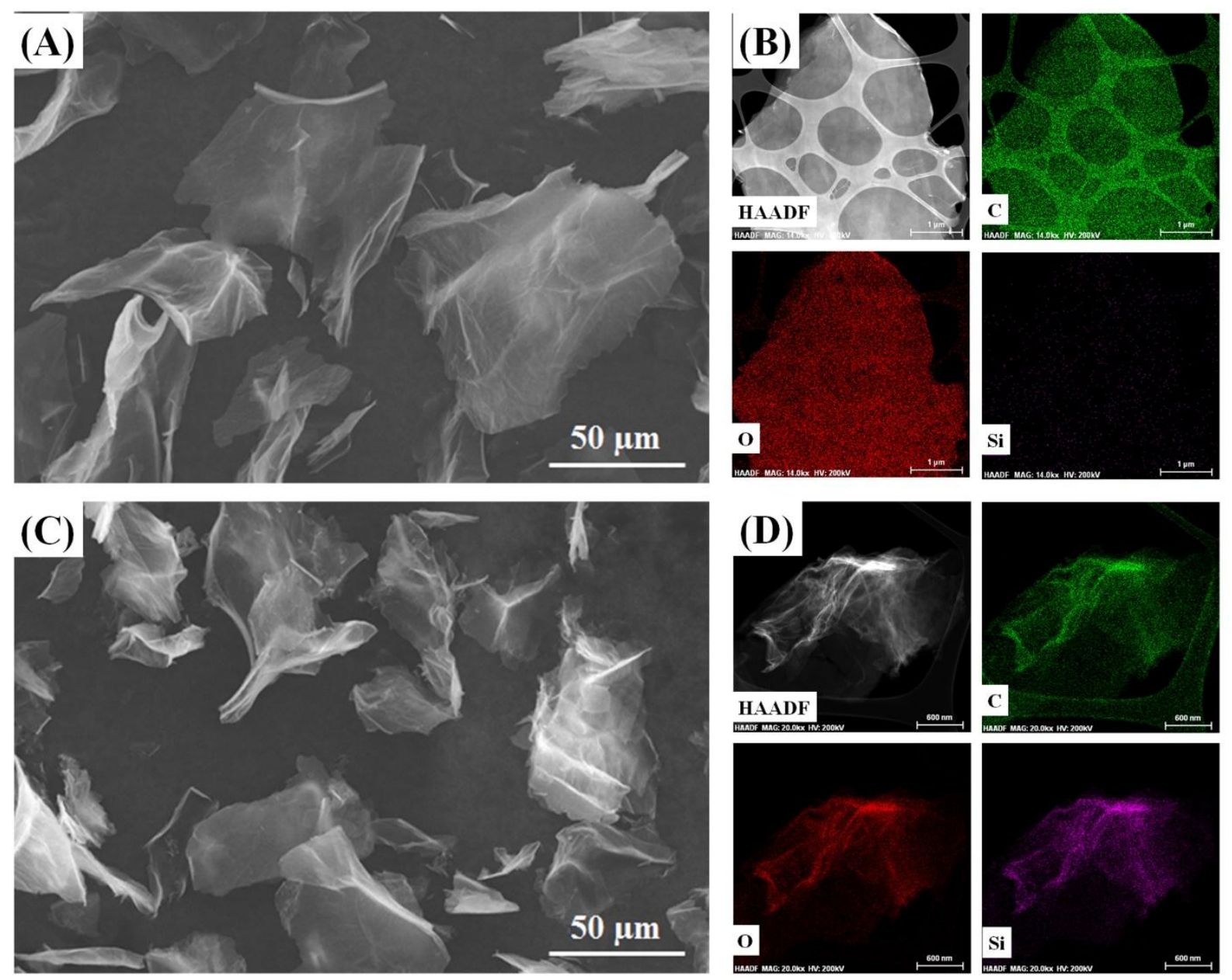

Figure 1 SEM images of (A) original GO and (C) $\mathrm{SiO}_{2} @ \mathrm{GO}$; HAADF-STEM image of (B) original GO and (D) $\mathrm{SiO}_{2} @ \mathrm{GO}$, and their corresponding EDX element maps of $\mathrm{C}, \mathrm{O}$ and $\mathrm{Si}$, respectively.

First, SEM and STEM measurements have been carried out to identify the morphologies of the original GO and the $\mathrm{SiO}_{2} @ \mathrm{GO}$. Figure 1(A) shows the pristine GO with a mean lateral size of $50 \mu \mathrm{m}$ and ultra-thin thickness. Figure 1B presents the HAADF image of pristine GO and the corresponding EDX elemental maps. As presented in Figure 1 (C), EDX has provided evidence that the $\mathrm{SiO}_{2} @ \mathrm{GO}$ has been successfully prepared in a water-alcohol mixture with sol-gel technique. $\mathrm{SiO}_{2}$ 
can be coated on the surface of GO, which is ascribed to the covalent reaction between TEOS and the functional groups (e.g., - $\mathrm{OH},-\mathrm{COOH},-\mathrm{COH})$ of $\mathrm{GO}$ [9]. Moreover, the morphology of $\mathrm{SiO}_{2} @ \mathrm{GO}$ does not change a lot compared with GO without $\mathrm{SiO}_{2}$. EDX results indicate that before deposited $\mathrm{SiO}_{2}$, in pristine $\mathrm{GO}$, the elemental mass ratio of $\mathrm{C}: \mathrm{O}: \mathrm{Si}$ is 80.35:19.58:0.07, while after deposited $\mathrm{SiO}_{2}$ layers, the elemental mass ratio of three elements became 49.00:32.39:18.61. Such an increase of Si ratio confirms the existence of $\mathrm{Si}$ in the $\mathrm{SiO}_{2} @ \mathrm{GO}$ and as shown in Figure 1 D, $\mathrm{SiO} 2$ has been homogeneously deposited on the surface of GO.
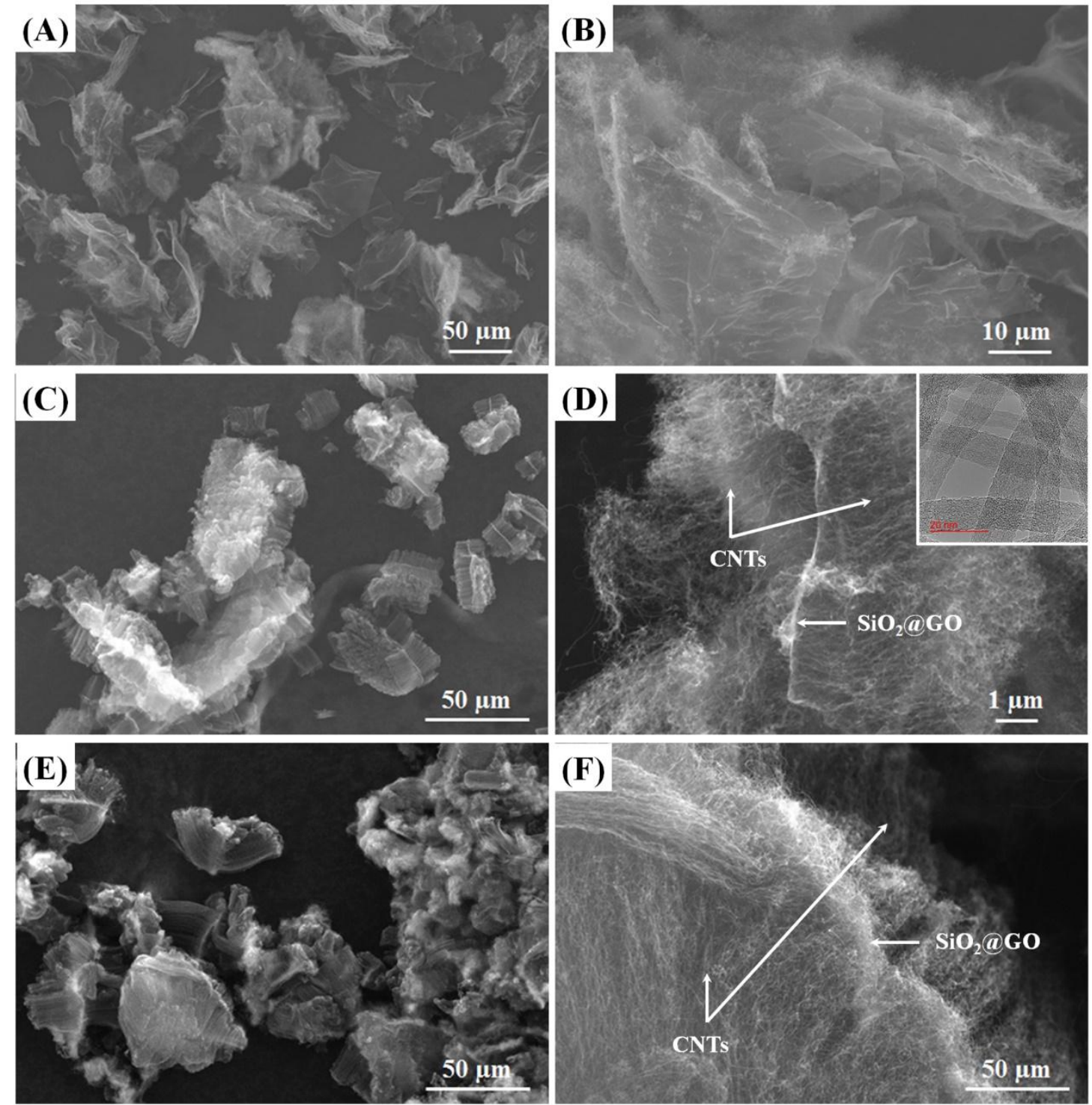

Figure 2 Morphological characterization of particles by using SEM and TEM: (A) and (B) shows the 5 min growth of CNTs on pristine GO; (C) and (D) shows the growth of CNTs on $\mathrm{SiO}_{2} @ \mathrm{GO}$ for 5 min, the insert image presents the diameter of CNTs; (E) and (F) shows the growth of CNTs on $\mathrm{SiO}_{2} @ \mathrm{GO}$ for $10 \mathrm{~min}$.

The growth of CNTs on different substrates has been achieved by a one-step CVD method using metalorganic compound ferrocene as catalyst precursor. Figure 2A presents the growth of CNTs on GO after 5 min. The major part of GO has no CNTs on the surface, only a small part of GO is covered by sparse CNTs. The enlarged region in Figure 2B shows the 
inhomogeneous CNTs growth, which is due to the poor wettability between graphite surface and catalyst particles. It is noteworthy that the CNT clusters grow perpendicularly onto the surface of individual $\mathrm{SiO}_{2} @ \mathrm{GO}$ (Figure 2C). The length and diameter of CNTs grown on the platelet surface are uniform with the length of about $5 \mu \mathrm{m}$ and the diameter of about $10 \mathrm{~nm}$, respectively. Figure 2D shows the high magnification image of hybrids. The edge and surface of $\mathrm{SiO}_{2} @ \mathrm{GO}$ platelet can be well distinguished in the hybrids, which indicates the array of CNTs on the platelet is very sparse synthesis for 5 min. Figure $2 \mathrm{E}$ and $2 \mathrm{~F}$ show the hybrids synthesized for $10 \mathrm{~min}$. Comparing to the hybrids grown for $5 \mathrm{~min}$, the grown CNT has longer length and much denser array on the platelets. Due to dense CNTs covered on the platelet, the edge and surface of the platelet is not obvious.
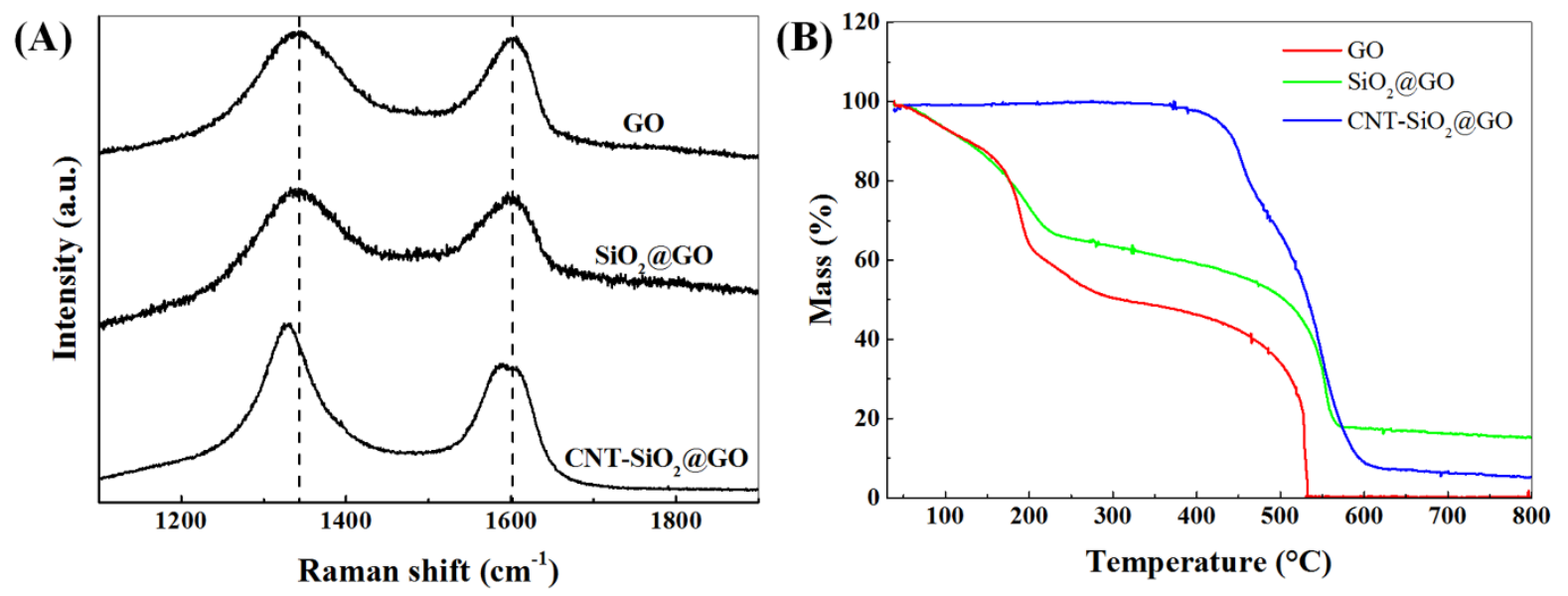

Figure 3 Basic characterization of GO, $\mathrm{SiO}_{2} @ \mathrm{GO}$ and $\mathrm{CNT}-\mathrm{SiO}_{2} @ \mathrm{GO}$ : (A) Raman spectra and (B) TGA analysis.

To get more precise structure and composition information about the pristine GO, the $\mathrm{SiO}_{2} @ \mathrm{GO}$ and the hybrids, Raman spectroscopy and TGA have been conducted and the results are presented in Figure 3. As shown in Figure 3A, the pristine GO and the $\mathrm{SiO}_{2} @ \mathrm{GO}$ display two characteristic peaks around 1343 and $1601 \mathrm{~cm}^{-1}$, corresponding to the typical D and G bands of the carbon species, respectively. The intensity ratio of D band over G band is usually used to quantify the graphitic ordering degree. After deposition of $\mathrm{SiO}_{2}$ layers, the $\mathrm{I}_{\mathrm{D}} / \mathrm{I}_{\mathrm{G}}$ value has no obvious change comparing to that of the pristine $\mathrm{GO}$. However, the D band has shifted to $1328 \mathrm{~cm}^{-1}$ for the hybrids, which is due to the growth of CNT on the platelet surface. As illustrated in Figure 3B of TGA, the curve of pristine GO is also displayed in Figure 3B. The pristine GO and $\mathrm{SiO}_{2} @ \mathrm{GO}$ exhibit a remarkable weight loss below $500{ }^{\circ} \mathrm{C}$, which is due to the decomposition of oxygen-containing groups on $\mathrm{GO}$ and the related disordered carbon atoms in the platelets. The weight loss of the pristine GO is $100 \%$ when the temperature is beyond $630{ }^{\circ} \mathrm{C}$. But after the deposition of $\mathrm{SiO}_{2}$ layers, the completely decomposition of GO structure has shifted to higher temperature, around $650{ }^{\circ} \mathrm{C}$ and the mass ratio of $\mathrm{SiO}_{2}$ in the hybrids is $18 \%$. Moreover, after CVD process, the GO has been completely reduced to RGO (reduced graphene oxide), which can be confirmed by the TGA curve since there has no noticeable weight loss below $400{ }^{\circ} \mathrm{C}$. The hybrids begin to decompose at $450{ }^{\circ} \mathrm{C}$, which is possibly corresponded to the decomposition of CNTs. A remarkable weight loss stage from $500{ }^{\circ} \mathrm{C}$ to $600{ }^{\circ} \mathrm{C}$ is corresponded to the decomposition of RGO structure and the rest CNTs. It is known that during the CVD synthesis process of hybrids, the high temperature in the 
furnace can not only offer the energy for chemical reaction but also accompany a thermal reduction effect which changes GO into RGO. Thus, the specific surface area of fillers and the conductivity (? ) of final hybrids can be increased effectively.

\section{Conclusion}

In summary, the $\mathrm{SiO}_{2} @ \mathrm{GO}$ hybrids have been first synthesized by a typical sol-gel method. Then, the CNT array has been grown on the surface of $\mathrm{SiO}_{2} @ \mathrm{GO}$ hybrids with uniform length by CVD method to form a 3D structure. The length and density of CNT array can be well controlled by the synthesis time. The strategy of the 3D structure design and optimization will contribute to achieving composites with higher performances and further drive the fabrication process to industrial scale.

\section{Acknowledgements}

This work was carried out within the MATMECA consortium and supported by the ANR under contract number ANR-10-

EQPX-37. It has benefited from the facilities of the Laboratory MSSMat (UMR CNRS 8579), CentraleSupélec, France. We thank Dr. P. Gemeiner for the Raman characterization. The pristine GO was kindly offered by GRAPHENE STANDRAD.

\section{References}

[1] A.K. Geim, K.S. Novoselov, The rise of graphene, Nature Materials 6 (2007) 183.

[2] S. Park, R.S. Ruoff, Chemical methods for the production of graphenes, Nature Nanotechnology 4 (2009) 217.

[3] X. Wang, L. Zhi, K. Müllen, Transparent, Conductive Graphene Electrodes for Dye-Sensitized Solar Cells, Nano Letters 8(1) (2008) 323-327.

[4] E. Zhou, J. Xi, Y. Guo, Y. Liu, Z. Xu, L. Peng, W. Gao, J. Ying, Z. Chen, C. Gao, Synergistic effect of graphene and carbon nanotube for high-performance electromagnetic interference shielding films, Carbon 133 (2018) 316-322.

[5] Y. Cheng, S. Lu, H. Zhang, C.V. Varanasi, J. Liu, Synergistic Effects from Graphene and Carbon Nanotubes Enable Flexible and Robust Electrodes for High-Performance Supercapacitors, Nano Letters 12(8) (2012) 4206-4211.

[6] Z. Fan, J. Yan, L. Zhi, Q. Zhang, T. Wei, J. Feng, M. Zhang, W. Qian, F. Wei, A three - dimensional carbon nanotube/graphene sandwich and its application as electrode in supercapacitors, Advanced materials 22(33) (2010) 37233728 .

[7] W. Li, A. Dichiara, J. Bai, Carbon nanotube-graphene nanoplatelet hybrids as high-performance multifunctional reinforcements in epoxy composites, Composites Science and Technology 74 (2013) 221-227.

[8] Y. Zeng, Y. Zhou, L. Kong, T. Zhou, G. Shi, A novel composite of SiO2-coated graphene oxide and molecularly imprinted polymers for electrochemical sensing dopamine, Biosensors and Bioelectronics 45 (2013) 25-33.

[9] L. Kou, C. Gao, Making silica nanoparticle-covered graphene oxide nanohybrids as general building blocks for large-area superhydrophilic coatings, Nanoscale 3(2) (2011) 519-528. 